Article

\title{
Novel Epigallocatechin-3-Gallate (EGCG)-Loaded Mesoporous Bioglass Scaffolds for Bone Recruitment Applications
}

\author{
Shih-Fu Ou ${ }^{1,+}\left(\mathbb{D}\right.$, Yuan-Li Tsao ${ }^{2,+}$, Wei-Chun Lin ${ }^{3}\left(\mathbb{C}\right.$, Yi-Ting Wang $^{3}$, Liping Wang ${ }^{4}\left(\mathbb{D}\right.$ and Fang-Yu Fan ${ }^{3, *}$ \\ 1 Department of Mold and Die Engineering, National Kaohsiung University of Science and Technology, \\ Kaohsiung 807, Taiwan; m9203510@nkust.edu.tw \\ 2 Department of Dentistry, Taipei Medical University-Shuang Ho Hospital, New Taipei City 235, Taiwan; \\ tinygoat@gmail.com \\ 3 School of Dental Technology, College of Oral Medicine, Taipei Medical University, Taipei 110, Taiwan; \\ weichun1253@tmu.edu.tw (W.-C.L.); M249108006@tmu.edu.tw (Y.-T.W.) \\ 4 UniSA Clinical \& Health Sciences, University of South Australia, Adelaide, SA 5001, Australia; \\ Liping.wang@mymail.unisa.edu.au \\ * Correspondence: fish884027@tmu.edu.tw \\ + These authors contributed equally to this work.
}

check for updates

Citation: Ou, S.-F.; Tsao, Y.-L.; Lin, W.-C.; Wang, Y.-T.; Wang, L.; Fan, F.-Y. Novel Epigallocatechin-3-Gallate (EGCG)-Loaded Mesoporous Bioglass Scaffolds for Bone Recruitment

Applications. Appl. Sci. 2021, 11, 243. https://doi.org/10.3390/app11010243

Received: 30 October 2020

Accepted: 24 December 2020

Published: 29 December 2020

Publisher's Note: MDPI stays neutral with regard to jurisdictional clai$\mathrm{ms}$ in published maps and institutional affiliations.

Copyright: (C) 2020 by the authors. Licensee MDPI, Basel, Switzerland. This article is an open access article distributed under the terms and conditions of the Creative Commons Attribution (CC BY) license (https:// creativecommons.org/licenses/by/ $4.0 /)$

\begin{abstract}
Bioglass-based material has been widely used in the field of biomedical science. In this study, the proper concentration of epigallocatechin-3-gallate (EGCG) for a mesoporous bioglass (MBG) scaffold was determined based on the sponge replication method. The fabrication procedure performed using a foam exchange technique resulted in an interconnected network of pores scaffolds with no cracks. In the minimum bactericidal concentrations of the bacteria assessed, the antibacterial concentration of EGCG against E. coli $(200 \mu \mathrm{g} / \mathrm{mL})$ was higher than that against S. aureus $(25 \mu \mathrm{g} / \mathrm{mL})$. The MBG and EGCG-MBG scaffolds exhibited excellent apatite mineralization and drug release abilities (the highest cumulative drug release from the EGCG-MBG scaffold was 75.37\%). Thus, a $200 \mu \mathrm{g} / \mathrm{mL}$ EGCG can prevent cell apoptosis and directly enhance cell proliferation. Hence, a low-dose EGCGMBG scaffold is another option for bone recruitment material.
\end{abstract}

Keywords: mesoporous bioglass scaffold; foam exchange technique; epigallocatechin-3-gallate; antibacterial; drug release

\section{Introduction}

Using suitable substitutes for damaged bone will improve the recruitment effect in clinical treatment. Bioceramics members that maintain the function of bone regeneration include bioglass, hydroxyapatite (HA), and tricalcium phosphate (TCP). Such different types of bioceramics have been used to prove that $\mathrm{Ca}^{2+}$ and $\left(\mathrm{PO}_{4}\right)^{3-}$ ions released from the surface of materials enhance apatite performance [1,2]. The cells such as mesenchymal stem cells, osteoblasts, and osteocytes perform the process of bone formation. The bioceramic graft plays the most important platform for wound healing and osteoinductive ability. Unlike other ceramics materials, the bioglass composition $\left(\mathrm{SiO}_{2}, \mathrm{CaO}\right.$, and $\left.\mathrm{P}_{2} \mathrm{O}_{5}\right)$ has a stronger bond with bone tissue due to rapid ion exchange. According to the tissue engineering principle, the porous shape of scaffolds possesses excellent properties, including cell performance and drug release abilities for inducing bone regeneration [3]. The fabricating methods of porous ceramics include solvent-casting particle leaching, freeze-drying, and the foam exchange technique. These manufacturing processes can replicate the 3D porous structure in bone tissue engineering [4-6]. Among these methods, the foam exchange technique is a simple strategy which can provide a highly interconnected structure.

An ideal bio-scaffold should possess antibacterial activity (at the former stage) and induce bone formation (at the latter stage) of the recruitment process after implantation. Based on the characteristics of bioglass, many studies have attempted to improve their abilities, specifically their mechanical loading, biological properties, and drug delivery 
rate [7-9]. The metal ions and medication combined with scaffolds have been proven to effectively increase antibacterial action. Using the photochemical generation method, Calabrese et al. synthesized silver particles (approximately $20 \mathrm{~nm}$ ) with an $\mathrm{Mg}-\mathrm{HA}$ scaffold. The nonfunctionalized scaffold displayed antibacterial activity of up to $99 \%$ (including against Gram-negative bacteria and Gram-positive bacteria) and excellent cell proliferation [10]. Similarly, the nano-copper deposition on 3D graphene scaffolds was fabricated by Zhang et al. [11]. Conversely, some antibiotics such as gentamicin, vancomycin, and chlorhexidine gluconate ( $\mathrm{CHX}$ ) are commonly used to load the scaffold. Ballarre et al. developed a multifunctional layer (chitosan-gelatin/silica-gentamicin) coating system for implant application. Another study by Rajabi investigated vancomycin and BMP-2included tricalcium phosphate $(\beta-\mathrm{TCP})$ /gelatin/bioglass scaffold and reported that a concentration of $5 \mathrm{mgL}^{-1}$ level could reduce Gram-positive bacterial infections by $80 \%$ [12-14]. Nevertheless, the general toxicities and drug release rates of these various additives are still being evaluated. As we know, epigallocatechin-3-gallate (EGCG) is the major ingredient (approximately 50-63\%) of catechins in green tea [15]. It is present in plant-based diets and offers many health benefits. Given its molecular structure, EGCG has positive functions, such as anti-oxidative, anti-inflammatory, and antimicrobial, and it can be used for medical development (as shown in Figure 1). The unique chemical structure (comprising eight hydroxyl groups $(\mathrm{OH})$ ) can help to remove the free radicals in the human body. The lesser the free radicals, the better and healthier are the cells. Forouzideh et al. showed that EGCG combined with silk fibroin nanofibers (SFNFs) using the electrospinning method can be used to engineer corneal tissue. Drug release from EGCG scaffolds was slow and controlled for over $144 \mathrm{~h}$. Additionally, these scaffolds could inhibit the proliferation of human umbilical vein endothelial cells (HUVEC) for limbal cells and avoid blindness [16]. Kuhne et al. compared the effects of EGCG and EGCG-PEGylated-PLGA nanoparticle systems for neuro-developmental treatment [17]. Many previous studies found green tea extracts would reduce the aging-induced bone loss. With a focus on bone graft reconstruction, cross-linked EGCG-modified collagen membranes have been created under freeze-dried conditions. The experimental group clearly prevented the migration of keratinocytes and did not affect osteoblast viability. After four weeks, the remodeling phase of bone healing (new bone formation) was demonstrated in rats [18]. Chen et al. has demonstrated that 1 and $10 \mu \mathrm{mol} / \mathrm{L}$ EGCG can enhance the expression of osteogenic genes [19]. The ovariectomized rats injected with $3.4 \mathrm{mg} / \mathrm{kg} /$ day EGCG for 3 months had improved bone structure and increased bone morphogenetic proteins expression [20]. The treatment with $10 \mu \mathrm{M}$ EGCG can enhance bone volume via the de novo bone formation [21]. Mah et al. also proved that a small amount of EGCG positively affected bone recruitment. Conversely, a higher concentration $(>0.5 \mathrm{mg} / \mathrm{mL})$ can reduce hard-tissue formation [22].<smiles>O=C(O[C@H]1Cc2c(O)cc(O)cc2O[C@H]1c1cc(O)c(O)c(O)c1)c1cc(O)c(O)c(O)c1</smiles>

Figure 1. The chemical structure of epigallocatechin-3-gallate (EGCG).

Therefore, the bioglass material is similar to the composition of natural bone. Choosing the material for preparing mesoporous scaffold is beneficial for its use as a drug carrier and bone regeneration. A highly interconnected porous scaffold can reproduce by foam exchange technique completely. Because the EGCG-MBG scaffold has not been applied to clinical studies before, this study has attempted to evaluate the effects of EGCG (the 
minimum inhibitory concentrations, MIC) on the proliferation of MG63 cells cultured in MBG scaffolds. It is believed that the functional scaffolds can be clinically applied for a novel bone recruitment method.

\section{Materials and Methods}

\section{1. $M B G$ Scaffold}

The MBG scaffolds were produced by the sponge replication method. In a nitric acid $\left(\mathrm{HNO}_{3}\right)$ solution system, the bioglass (molar ratios: $\left.\mathrm{Si} / \mathrm{Ca} / \mathrm{P}=60 / 36 / 4\right)$ precursor included $13.2 \mathrm{~mL}$ of tetraethoxysilane (TEOS), $0.7 \mathrm{~mL}$ of triethyl phosphate (TEP), and $5.8 \mathrm{~g}$ of calcium nitrate tetrahydrate $\left(\mathrm{Ca}\left(\mathrm{NO}_{3}\right)_{2} \cdot 4 \mathrm{H}_{2} \mathrm{O}\right)$ in $9.5 \mathrm{~mL}$ of deionized water that was wellstirred to maintain a uniform solution. All chemical reagents were purchased from Sigma Corporation (St. Louis, MO, USA). The polyurethane (PU) foam was purchased from a local market (approximately 5-mm cubic size) and used as the template in the bioglass slurry. After impregnation, the foam was removed and centrifuged to remove the extra precursor solution. These dips and compressing steps were repeated four times to ensure uniform coating on the struts. Then, the block was dried at $60^{\circ} \mathrm{C}$ for $1 \mathrm{~h}$. These coating procedures were repeated four times until the bioglass slurry was completely absorbed. Finally, the PU foam was heated to $700{ }^{\circ} \mathrm{C}\left(5^{\circ} \mathrm{C} / \mathrm{min}\right)$ and maintained for $0.5 \mathrm{~h}$ in a sintering furnace.

\subsection{Characterization}

The crystalline phases and microstructures of the scaffolds were analyzed using X-Ray diffractometer (XRD; Rigaku, TTRAXIII, Tokyo, Japan). An X-ray diffractometer with a monochromatic $\mathrm{Cu} \mathrm{K} \alpha$ radiation ( $45 \mathrm{kV}$ and $40 \mathrm{~mA}$ ) was used and XRD patterns were recorded between the $2 \theta$ interval ranges from $20^{\circ}$ to $60^{\circ}$ (scan speed: $4^{\circ} / \mathrm{min}$, step scan: $0.03^{\circ}$ ). The crystalline phases were identified using a Joint Committee on Powder Diffraction Standards (JCPDS) card. The structure of the scaffold was observed by scanning electron microscopy (SEM; SU3500, HITACHI, Tokyo, Japan). After copper coating for $1 \mathrm{~min}$, the microstructure of the scaffolds was observed at $40 \mathrm{kV}$. Additionally, the scaffolds were dried and placed in isotherm system under $120^{\circ} \mathrm{C}$ for $4 \mathrm{~h}$ to degas. The porous classification of the bioglass scaffolds was measured with a nitrogen $(77 \mathrm{~K})$ adsorption/desorption isotherm system (Belsorp max, Microtrac, Montgomeryville, USA). On the other hand, the pore volume and diameter were determined using the Barett-Joyner-Halenda method $(\mathrm{BJH})$ method from the adsorption branches.

\subsection{Antibacterial Activity of EGCG}

The antibacterial activity (MIC) of EGCG (Sigma, St. Louis, MO, USA) was determined by the microdilution method. E. coli (BCRC 11849) and S. aureus (BCRC 10781) were purchased from the Bioresource Collection and Research Center (Hsinchu, Taiwan). Before the experiment, the tools and media were autoclaved at $121^{\circ} \mathrm{C}$ for 15 min with standard atmosphere (1 atm). In the agar dilution method, $4 \mathrm{~mL}$ of Luria-Bertani agar (LA, Sigma, St. Louis, MO, USA) solution containing $1 \mathrm{~mL}$ of EGCG doubling diluting agent was solidified in a 6-cm dish plate. The bacterial colonies of E. coli and S. aureus from the stock solutions were separately incubated in $2 \mathrm{~mL}$ of nutrient broth overnight at $37^{\circ} \mathrm{C}$. The next day, $50 \mu \mathrm{L}$ of the diluted bacterial suspension $\left(1 \times 10^{4} \mathrm{cell} / \mathrm{mL}\right)$ was added to the agar plate, spread thoroughly, and incubated for $24 \mathrm{~h}$. After incubation, the number of colonies were observed at each concentration of EGCG.

\subsection{EGCG-MBG Scaffold}

The scaffolds fabricated by the sponge replication method were divided into two groups. Unlike the control groups, the experimental groups were immersed in the antibiotic concentration of the EGCG solution $(200 \mu \mathrm{g} / \mathrm{mL})$ for $24 \mathrm{~h}$. After being sieved through a filter paper, the EGCG-modified scaffolds were rinsed three times with deionized water and then dried overnight. To determine the bioactivity behaviors, both scaffolds were immersed in simulated body fluid (SBF) for 14 and 28 days. The SBF composition was made according 
to the protocol described by Kokubo et al. [23]. After immersing, the phase structure was characterized by the XRD pattern.

\subsection{Release of EGCG}

In order to understand the encapsulate of EGCG-MBG scaffolds, the calibration curves with different EGCG concentrations were initially evaluated. The absorbance value of $0.002,0.004,0.0078,0.0156,0.0312,0.0625$, and $0.125,0.25 \mathrm{mg} / \mathrm{mL}$ concentration in the phosphate-buffered saline (PBS) solution was recorded using the Varioskan Flash reader (Thermo Fisher Scientific, Massachusetts, USA).

Based on the calibration curve information, we could estimate the encapsulation and cumulative release efficiency of EGCG-MBG scaffolds. To simulate the in vivo placement, the 20-mg EGCG-MBG scaffolds were immersed in $10 \mathrm{~mL}$ of PBS solution at $37^{\circ} \mathrm{C}$. At every measuring time point $(2,4,10,24,48,72,96,120,240$, and $360 \mathrm{~h}), 5 \mathrm{~mL}$ of buffer solution was withdrawn and replaced with the same amount of fresh solution. Then, the EGCG released scaffold was recorded using the absorbance reader with a $274 \mathrm{~nm}$ wavelength. The cumulative release of EGCG was calculated as follows:

$$
\text { Cumulative release efficiency }(\%)=\mathrm{A} / \mathrm{B} \times 100
$$

where $\mathrm{A}$ is the encapsulated number of scaffolds during the measurement time and $\mathrm{B}$ is the encapsulated number of scaffolds before immersion.

\subsection{Cell Live Assay}

The proliferation of the MG63 cells was analyzed with the Cell Counting Kit-8 (CCK-8; Sigma, Taipei, Taiwan) assay. In this assay, a highly water-soluble tetrazolium salt solution containing 2-(2-methoxy-4-nitrophenyl)-3-(4-nitrophenyl)-5-(2,4-disulfophenyl)-2Htetrazolium is reduced to Formazan dye (yellow) by dehydrogenase. The color of the Formazan dye depends on the cell viability. Thus, $100 \mu \mathrm{L}$ of $1 \times 10^{4} \mathrm{cell} / \mathrm{mL}$ of the MG63 cell suspension was cultured on a 96 -well plate at $37^{\circ} \mathrm{C}\left(5 \% \mathrm{CO}_{2}\right.$ in the humidified incubator) for $24 \mathrm{~h}$. Before the CCK-8 test, the MBG and EGCG-MBG scaffolds immersed in Dulbecco's Modified Eagle Medium (DMEM) solution for $24 \mathrm{~h}$. After 1 day, the medium was centrifuged $(2000 \mathrm{rpm}, 10 \mathrm{~min})$ and sieved through a $0.22-\mu \mathrm{m}$ filter. The extraction medium was prepared with the MBG and EGCG-MBG scaffolds as the experimental group. Furthermore, the same amount of medium (no cells) was present to indicate background performance and the medium with cells in a well as the control group. After adding $100 \mu \mathrm{L}$ of the medium for 1 day, $10 \mu \mathrm{L}$ of the CCK solution was provided to each well and incubated for $2 \mathrm{~h}$. The absorbance was measured at different time intervals ( 24 and $48 \mathrm{~h}$ ) using a microplate reader (BioTek Epoch, Winooski, VT, USA) at $450 \mathrm{~nm}$. The percentage of cell viability was estimated by the following equation:

$$
\text { Survival rate }(\%)=(A-B) /(C-B) \times 100
$$

in which $\mathrm{A}$ is the mean absorbance value of the experimental group in the culture plate, $\mathrm{B}$ is the mean absorbance value of the background group (only medium without cells in a well) in the culture plate, and $C$ is the mean absorbance value of the control group (medium and cells in a well) in the culture plate.

\subsection{Statistical Analysis}

Cell viability was analyzed with SPSS 19.0 software (Released 2010, IBM, Armonk, New York). The Mann-Whitney U test was used to compare the bioactivity and viability of the cells with different treatments. A significant difference was considered when $p<0.05$.

\section{Results and Discussion}

\subsection{Characterization of the MBG Scaffold}

The crystalline phases of the mesoporous scaffolds are shown on the XRD patterns in Figure 2A. The figure indicates that the MBG scaffolds could be successfully fabricated 
by the sponge replication method. The standard amorphous silica peak was observed at $2 \theta=22^{\circ}$ (JCPDS No. 29-0085). Figure 2A(a,b) shows the morphology of the scaffolds before and after being sintered at $700^{\circ} \mathrm{C}$. The PU foam possesses a microporous structure between the neighboring struts of approximately $300-480 \mu \mathrm{m}$. After being impregnated with the bioglass slurry and sintered procedure, the scaffolds had an interconnected network of pores; these were preserved and no cracks appeared on the surface. These pores should be adequate to allow cell penetration and control the rate of drug release [24]. The nitrogen adsorption measurement is used to characterize porous material (as shown in Figure 2B). According to the classical approach, the capillary condensation was observed from the corresponding Type IV isotherm at relative pressure. It was assumed that the mesoporous behavior that always accompanies the hysteresis model occurred. The hysteresis loop from the desorption cycle of the MBG scaffold contributed to the disk-shaped (H3) silts. The BJH analysis can be employed to determine the pore size distribution of the MBG scaffold. The small image in Figure 2B has shown the mesoporous material of the MBG scaffold sample containing pores in the range $10-20 \mathrm{~nm}$. This pore size has proven advantageous for the uptake and release of drugs, growth factors, and improved cell attachment [25].
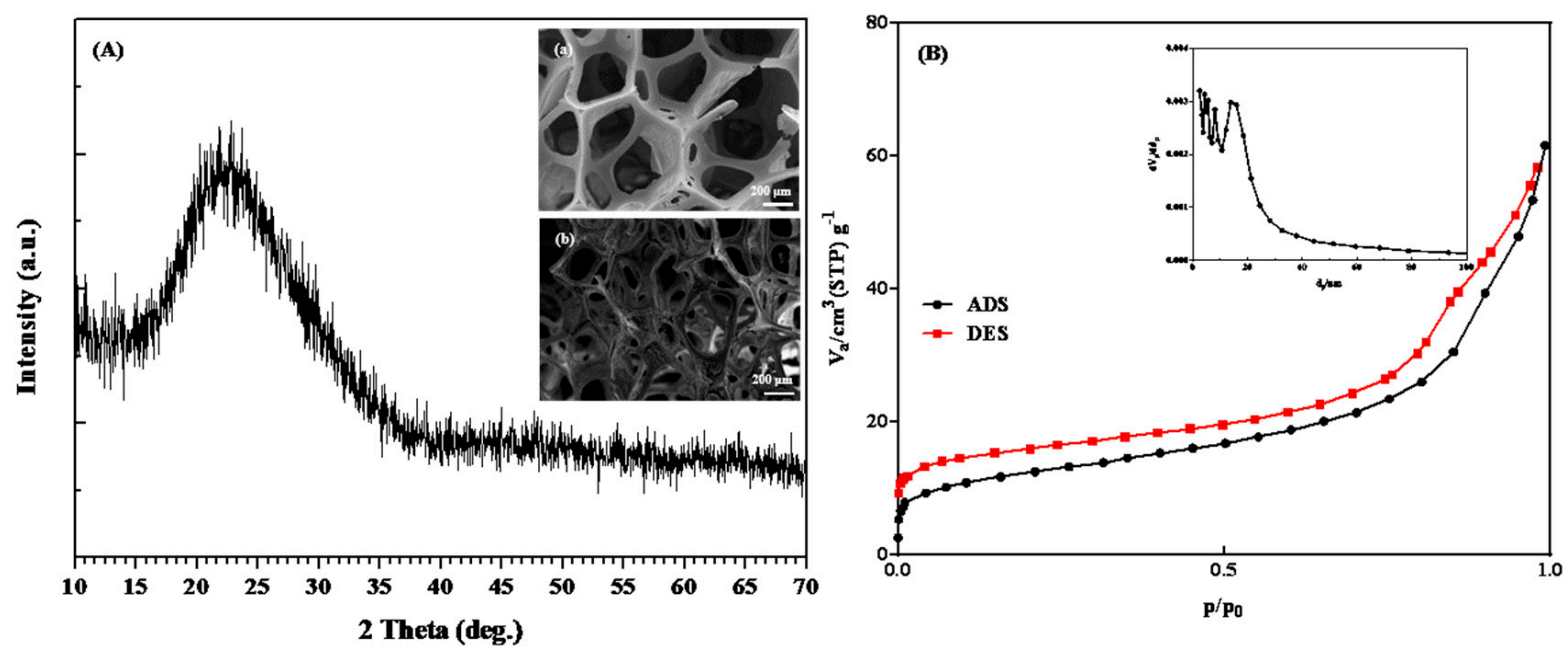

Figure 2. (A)The XRD patterns and SEM images of the mesoporous bioglass (MBG) scaffolds before (a) and after (b) sintering at $700{ }^{\circ} \mathrm{C}$. (B)The isotherm measurement and Barett-Joyner-Halenda (BJH) porous size distribution of the MBG scaffold.

\subsection{Antibacterial Assessment of EGCG}

The agar dilution method was used to examine the minimum bactericidal concentration of E. coli and S. aureus. Figure 3 illustrates the relationship between the colony growth of E. coli and the EGCG concentration. When the EGCG concentration reached $200 \mu \mathrm{g} / \mathrm{mL}$, the number of bacteria decreased significantly. The growth of $S$. aureus (Gram-positive) compared with the Gram-negative bacteria group is shown in Figure 4. The MIC to antibiotics with EGCG was $25 \mu \mathrm{g} / \mathrm{mL}$. The antibacterial concentration against $S$. aureus was lower than that against $E$. coli. These results may have occurred because Gram-negative bacteria have cell wall (outer membrane) components [26]. In this study, a concentration of $200 \mu \mathrm{g} / \mathrm{mL}$ (the highest antibiotic concentration) was chosen for the fabricated EGCG-MBG scaffold. 

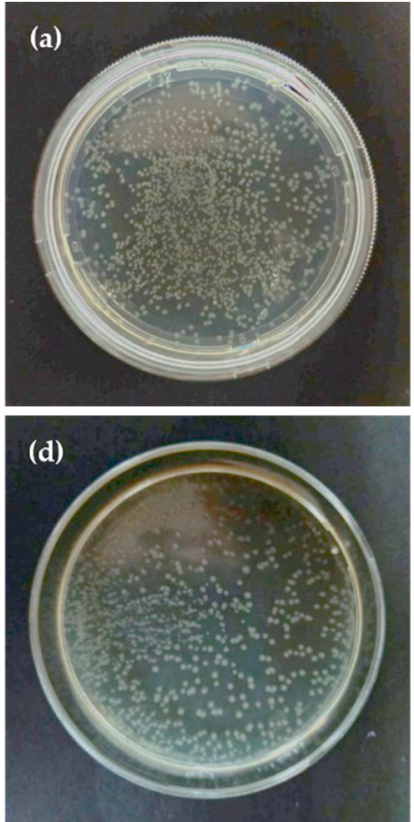
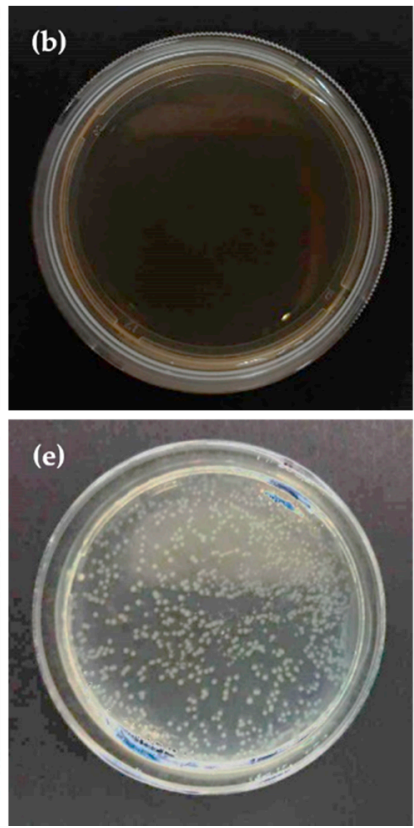
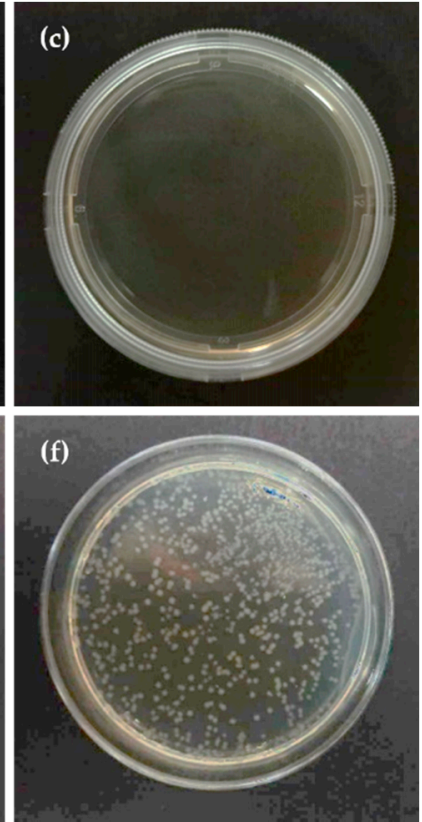

Figure 3. Bacteria colonies of E. coli after exposure to different concentrations of EGCG. (a) 0, (b) 400, (c) 200, (d) 100, (e) 50, and (f) $25 \mu \mathrm{g} / \mathrm{mL}$.
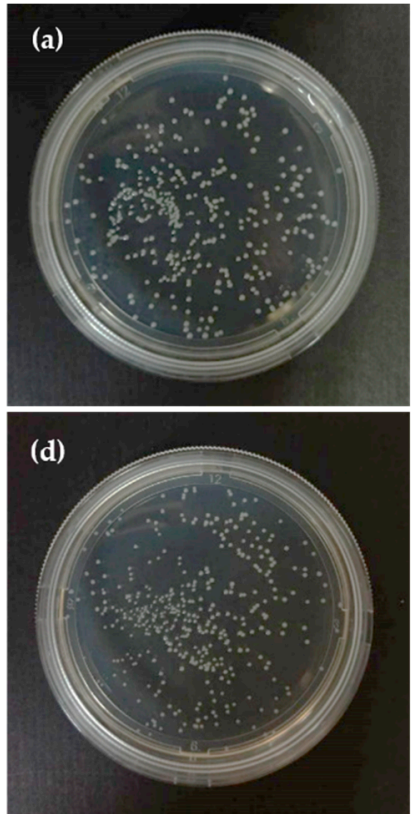
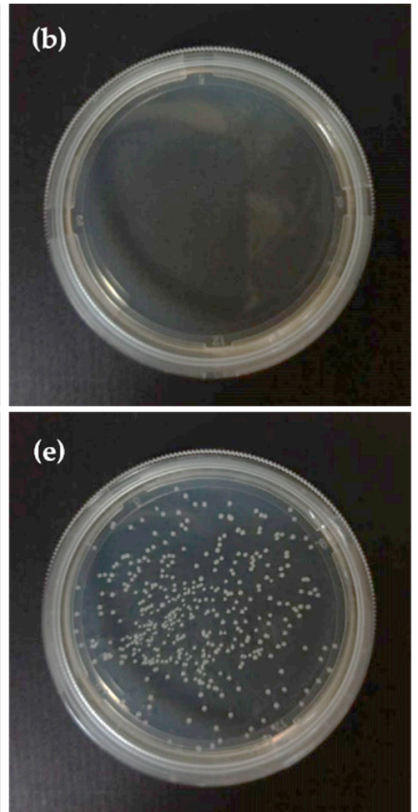
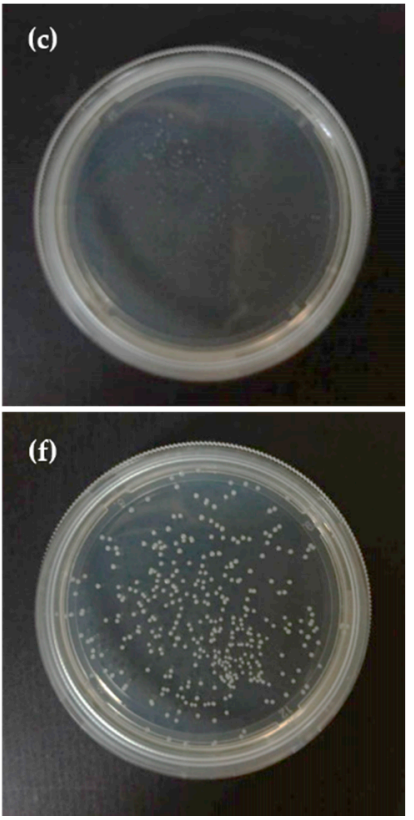

Figure 4. Bacteria colonies of $S$. aureus after exposure to different concentrations of EGCG. (a) 0 , (b) 50, (c) 25, (d) 1.2, (e) 0.5 , and (f) $0.3 \mu \mathrm{g} / \mathrm{mL}$.

\subsection{The Bioactivity of the EGCG-MBG Scaffold}

The bioglass-based material has excellent osteoconductive ability because its composition leads to the formation of HA. Generally, the bioactivity of scaffolds can be evaluated by immersion in SBF solution. Figure 5a shows the phase patterns of the MBG and EGCGMBG scaffolds after soaking in SBF for 14 and 28 days. The MBG scaffolds presented an amorphous structure before the bioactivity investigation. At the beginning of the study, the peak intensity depended on the soaking time. The apatite peaks at $2 \theta=32^{\circ}(211)$ and $46.7^{\circ}$ (222) appeared on all of the scaffold surfaces. The apatite peaks have a significant difference between MBG and EGCG-MBG groups $(p<0.05)$. The morphology of the apatite was observed by SEM (as shown in Figure $5 b, c)$. The amount of nano-structured apatite formed 
on the surface of the scaffolds after being immersed in SBF for 28 days was determined. Therefore, the MBG and EGCG-MBG scaffolds exhibited apatite mineralization abilities.

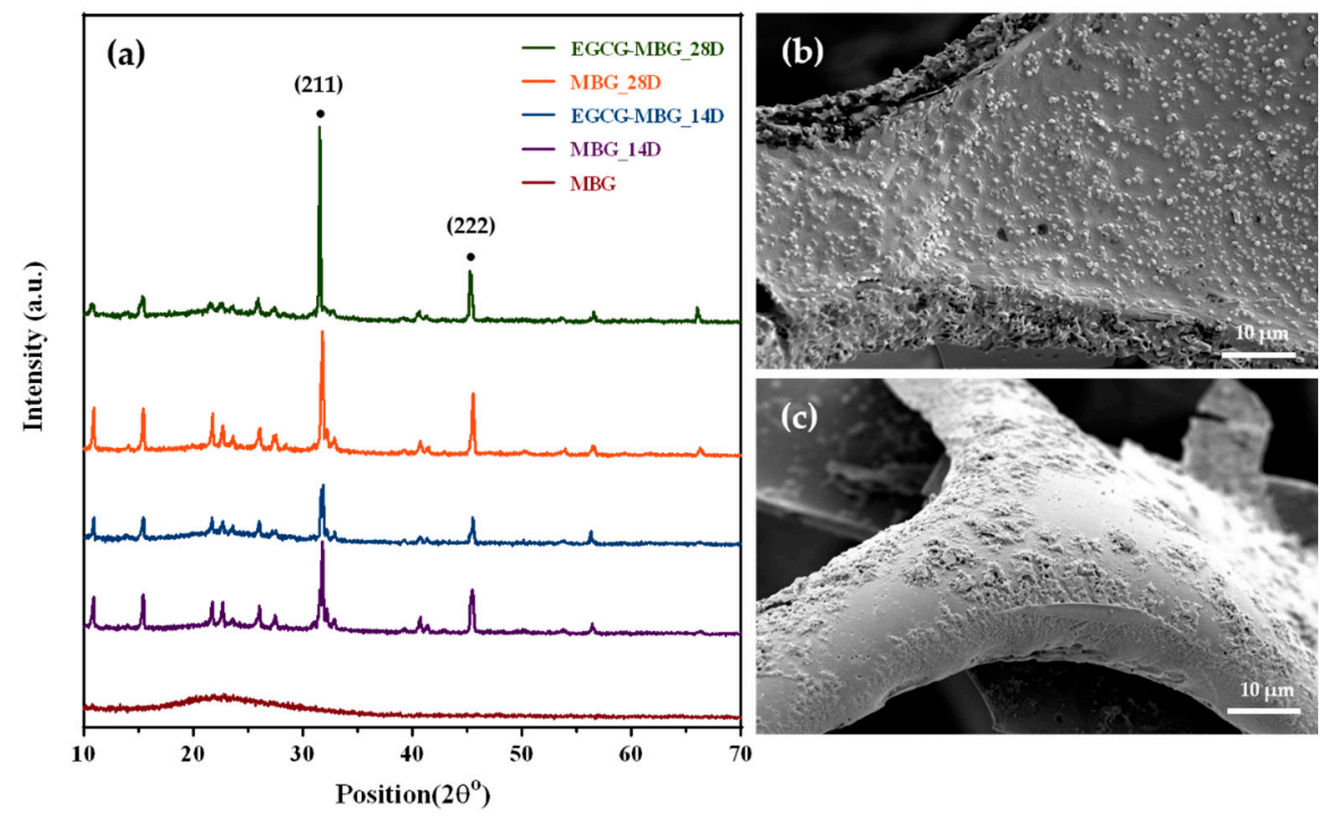

Figure 5. The XRD patterns (a) and SEM images of the MBG (b) and EGCG-MBG (c) scaffolds in SBF solution at 28 days.

\subsection{Drug Release of EGCG-MBG}

The absorbance value with different EGCG concentration was measured at $274 \mathrm{~nm}$. After calibration, it was noted to have a linear relationship with $\mathrm{R}^{2}$ value of 0.9999 (Figure 6a). The drug release properties of the EGCG-MBG scaffold were monitored through immersion in PBS solution at $37^{\circ} \mathrm{C}$. As shown in Figure 6b, the release rate was high during the initial $24 \mathrm{~h}$. The cumulative drug release rate reached $68.71 \%$. By contrast, the release efficiency was lower and displayed a stable performance. The highest release rate of the EGCG-MBG scaffold was $75.37 \%$. More importantly, the mesoporous structure offered the possibility of maintaining the EGCG concentration at an effective dose for a long time.
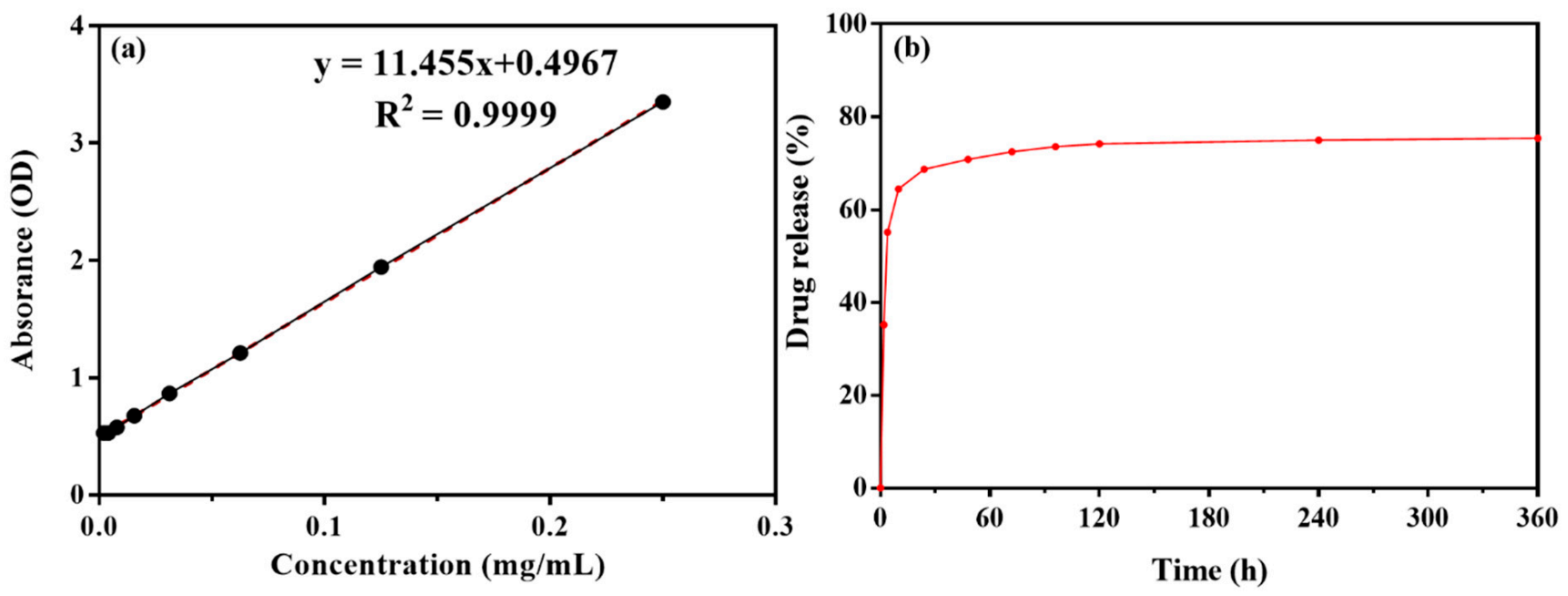

Figure 6. (a)The calibration curve of $0.002,0.004,0.0078,0.0156,0.0312,0.0625,0.125,0.25 \mathrm{mg} / \mathrm{mL}$ of EGCG. (b)The cumulative drug release efficiency of the EGCG-MBG scaffolds as time goes by. 


\subsection{Cytocompatibility of Scaffolds}

The cytotoxicity of the MBG and EGCG-MBG scaffolds was evaluated by the CCK-8 assay. Figure 7 shows the effect of these scaffolds on cell viability. The survival rate of the MBG scaffold was $90.15 \%$ and $97.44 \%$ at 24 and 48 h, respectively. Whereas, the EGCGMBG scaffold displayed a higher proliferation than the MBG scaffold $(104.36 \%$ and $107.52 \%$ for 1 and 2 days, respectively). The cell proliferation results of MG63 behavior showed a significant difference between MBG and EGCG-MBG groups $(p<0.05)$ [27]. Therefore, the proper concentration of EGCG $(200 \mu \mathrm{g} / \mathrm{mL})$ can prevent cell apoptosis and directly enhance cell proliferation. It could be speculated that the chemical structure of EGCG with MBG scaffolds would remove the free radicals quickly and protect the cell viability.

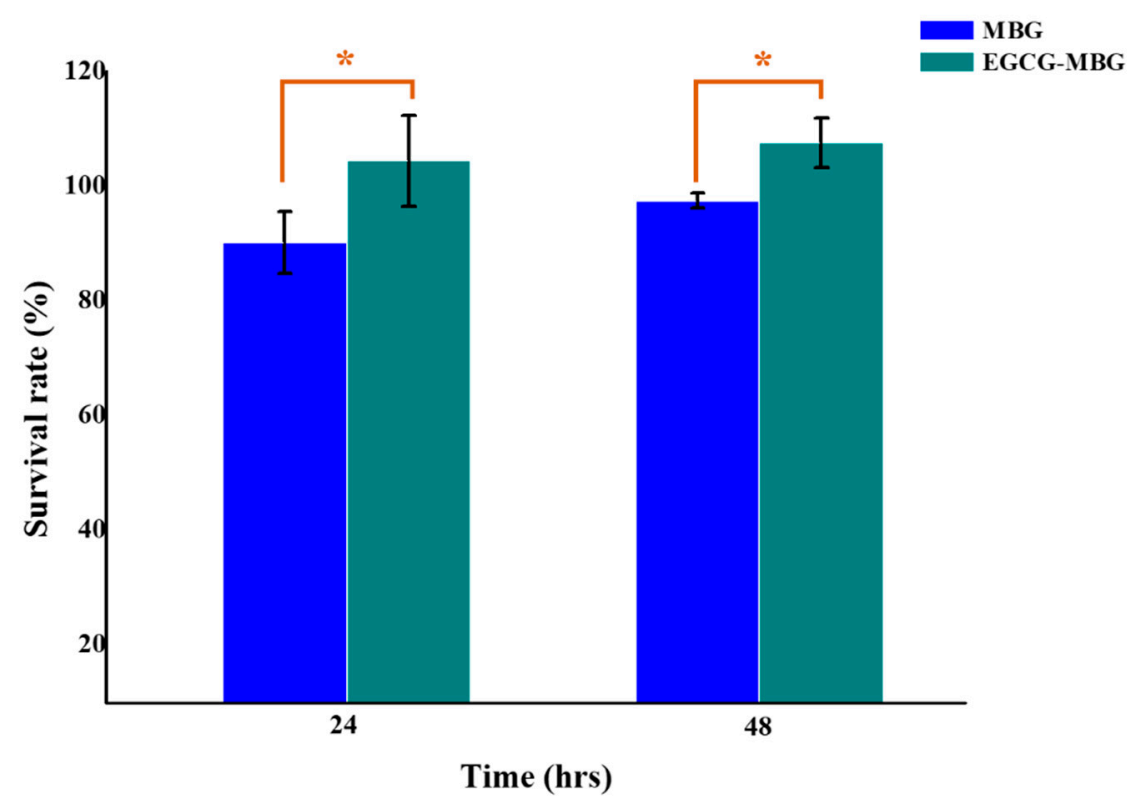

Figure 7. Cytotoxicity of the MBG and EGCG-MBG scaffolds at 24 and $48 \mathrm{~h},\left(^{*} p<0.05\right)$.

\section{Conclusions}

In this study, we fabricated the EGCG-MBG scaffolds successfully using the sponge replication method. These newly fabricated scaffolds possess an interconnected network of pores and have a smoother surface. The EGCG-MBG scaffolds also exhibited apatite mineralization abilities in SBF solution for 28 days. Furthermore, $200 \mu \mathrm{g} / \mathrm{mL}$ EGCG can prevent cell apoptosis and directly enhance cell proliferation in vitro. The release rate of EGCG was burst within $24 \mathrm{~h}$ and displayed a stable performance for $360 \mathrm{~h}$. Although the activity of EGCG is concerning, the release rate of the EGCG-MBG scaffold can reach a stable situation for 15 days. Hence, it is believed that EGCG-MBG scaffolds are promising materials for clinical applications.

Author Contributions: Writing—original draft, F.-Y.F.; investigation, Y.-L.T.; data curation, W.-C.L.; methodology, Y.-T.W.; validation, L.W.; writing-review and editing, S.-F.O. and F.-Y.F. All authors have read and agreed to the published version of the manuscript.

Funding: The authors acknowledge the technical support provided by TMU Core Facility. This research was also supported in part by Grant MOST 108-2221-E-038-016-MY2.

Data Availability Statement: The data presented in this study are available on request from the corresponding author.

Conflicts of Interest: The authors declare no conflict of interest in this work. 


\section{References}

1. Zhu, Q.; Ablikim, Z.; Chen, T.; Cai, Q.; Xia, J.; Jiang, D.; Wang, S. The preparation and characterization of HA/ B-TCP biphasic ceramics from fish bones. Ceram. Int. 2017, 43, 12213-12220. [CrossRef]

2. Ma, J.; Huang, B.X.; Zhao, X.C.; Wang, C.Z.; Zhang, H.M. Effect of zinc substitution for calcium on the structure, dissolution behavior and apatite formation of CaO-ZnO-SiO2-P2O5 bioceramics. Mater. Lett. 2017, 206, 154-157. [CrossRef]

3. Xu, Y.; Gao, D.; Feng, P.; Gao, C.; Pengcd, S.; Ma, H.; Yang, S.; Shuai, C. A mesoporous silica composite scaffold: Cell behaviors, biomineralization and mechanical properties. Appl. Surf. Sci. 2017, 423, 314-321. [CrossRef]

4. Wu, F.; Liu, C.; O'Neill, B.; Wei, J.; Ngothai, Y. Fabrication and properties of porous scaffold of magnesium phosphate/polycaprolactone biocomposite for bone tissue engineering. Appl. Surf. Sci. 2012, 258, 7589-7595. [CrossRef]

5. Wers, E.; Oudadesse, H.; Lefeuvre, B.; Merdrignac-Conanec, O.; Barroug, A. Evalution of the kinetic and relaxation time of gentamicin sulfate released from hybrid biomaterial bioglass-chitosan scaffolds. Appl. Surf. Sci. 2015, 353, 200-208. [CrossRef]

6. Wang, Q.; Tang, P.; Ge, X.; Li, P.; Lv, C.; Wang, M.; Wang, K.; Fang, L.; Lu, X. Experimental and simulation studies of strontium/zinccodoped hydroxyapatite porous scaffolds with excellent osteoinductivity and antibacterial activity. Appl. Surf. Sci. 2018, 462, 118-126. [CrossRef]

7. $\quad$ Řehořek, L.; Chlup, Z.; Meng, D.; Yunos, D.; Boccaccini, A.; Dlouhy, I. Response of $45 S 5$ Bioglass ${ }^{\circledR}$ foams to tensile loading. Ceram. Int. 2013, 39, 8015-8020. [CrossRef]

8. Chen, X.; Li, S.; Yan, Y.; Su, J.; Wang, D.; Zhao, J.; Wang, S.; Zhang, X. Absorbable nanocomposites composed of mesoporous bioglass nanoparticles and polyelectrolyte complexes for surgical hemorrhage control. Mater. Sci. Eng. C 2020, 109, 110556. [CrossRef]

9. Shoaib, M.; Saeed, A.; Rahman, M.S.U.; Naseer, M.M. Mesoporous nano-bioglass designed for the release of imatinib and in vitro inhibitory effects on cancer cells. Mater. Sci. Eng. C 2017, 77, 725-730. [CrossRef]

10. Calabrese, G.; Petralia, S.; Franco, D.; Nocito, G.; Fabbi, C.; Forte, L.; Guglielmino, S.; Squarzoni, S.; Traina, F.; Conoci, S. A new Agnanostructured hydroxyapatite porous scaffold: Antibacterial effect and cytotoxicity study. Mater. Sci. Eng. C 2021, 118, 111394. [CrossRef]

11. Zhang, J.; Zhu, S.; Song, K.; Wang, Z.; Han, Z.; Zhao, K.; Fan, Z.; Zhou, X.; Zhang, Q. 3D reduced graphene oxide hybrid nano-copper scaffolds with a high antibacterial performance. Mater. Lett. 2020, 267, 127527. [CrossRef]

12. Ballarre, J.; Aydemir, T.; Liverani, L.; Roether, J.; Goldmann, W.; Boccaccini, A.R. Versatile bioactive and antibacterial coating system based on silica, gentamicin, and chitosan: Improving early stage performance of titanium implants. Surf. Coat. Technol. 2020, 381, 125138. [CrossRef]

13. Rajabi, A.; Esmaeili, A. Preparation of three-phase nanocomposite antimicrobial scaffold BCP/Gelatin/45S5 glass with drug vancomycin and BMP-2 loading for bone regeneration. Colloids Surf. A Physicochem. Eng. Asp. 2020, 606, 125508. [CrossRef]

14. El-Sayed, S.A.; Mabrouk, M.; Khallaf, M.E.; El-Hady, B.M.A.; El-Meliegy, E.; Shehata, M.R. Antibacterial, drug delivery, and osteoinduction abilities of bioglass/chitosan scaffolds for dental applications. J. Drug Deliv. Sci. Technol. 2020, 57, 101757. [CrossRef]

15. Cabrera-Vique, C.; Artacho, R.; Giménez, R. Beneficial Effects of Green Tea-A Review. J. Am. Coll. Nutr. 2006, 25, 79-99. [CrossRef] [PubMed]

16. Forouzideh, N.; Nadri, S.; Fattahi, A.; Abdolahinia, E.D.; Habibizadeh, M.; Rostamizadeh, K.; Baradaran-Rafii, A.; Bakhshandeh, H. Epigallocatechin gallate loaded electrospun silkfibroin scaffold with anti-angiogenic properties for corneal tissue engineering. J. Drug Deliv. Sci. Technol. 2020, 56, 101498. [CrossRef]

17. Kühne, B.A.; Puig, T.; Ruiz-Martínez, S.; Crous-Masó, J.; Planas, M.; Feliu, L.; Cano, A.; García, M.L.; Fritsche, E.; Llobet, J.M.; et al. Comparison of migration disturbance potency of epigallocatechin gallate (EGCG) synthetic analogs and EGCG PEGylated PLGA nanoparticles in rat neurospheres. Food Chem. Toxicol. 2019, 123, 195-204. [CrossRef]

18. Chu, C.; Wang, Y.; Wang, Y.; Yang, R.; Liu, L.; Rung, S.; Xiang, L.; Wu, Y.; Du, S.; Man, Y.; et al. Evaluation of epigallocatechin3-gallate (EGCG) modified collagen in guided bone regeneration (GBR) surgery and modulation of macrophage phenotype. Mater. Sci. Eng. C 2019, 99, 73-82. [CrossRef]

19. Chen, C.-H.; Ho, M.-L.; Chang, J.-K.; Hung, S.-H.; Wang, G.-J. Green tea catechin enhances osteogenesis in a bone marrow mesenchymal stem cell line. Osteoporos. Int. 2005, 16, 2039-2045. [CrossRef]

20. Chen, C.-H.; Kang, L.; Lin, R.-W.; Fu, Y.-C.; Lin, Y.-S.; Chang, J.-K.; Chen, H.-T.; Chen, C.-H.; Lin, S.-Y.; Wang, G.-J.; et al. (-)-Epigallocatechin-3-gallate improves bone microarchitecture in ovariectomized rats. Menopause 2013, 20, 687-694. [CrossRef]

21. Lin, S.-Y.; Kang, L.; Chen, J.-C.; Wang, C.-Z.; Huang, H.H.; Lee, M.-J.; Cheng, T.-L.; Chang, C.-F.; Lin, Y.-S.; Chen, C.-H. (-)-Epigallocatechin3-gallate (EGCG) enhances healing of femoral bone defect. Phytomedicine 2019, 55, 165-171. [CrossRef] [PubMed]

22. Mah, Y.-J.; Song, J.S.; Kim, S.-O.; Lee, J.-H.; Jeon, M.; Jung, U.-W.; Moon, S.J.; Kim, J.-H.; Choi, H.-J. The effect of epigallocatechin3-gallate (EGCG) on human alveolar bone cells both in vitro and in vivo. Arch. Oral Biol. 2014, 59, 539-549. [CrossRef] [PubMed]

23. Kokubo, T.; Takadama, H. How useful is SBF in predicting in vivo bone bioactivity? Biomaterials 2006, 27, 2907-2915. [CrossRef] [PubMed]

24. Rainer, A.; Giannitelli, S.M.; Abbruzzese, F.; Traversa, E.; Licoccia, S.; Trombetta, M. Fabrication of bioactive glass-ceramic foams mimicking human bone portions for regenerative medicine. Acta Biomater. 2008, 4, 362-369. [CrossRef] [PubMed]

25. Baino, F.; Fiorilli, S.; Vitale-Brovarone, C. Bioactive glass-based materials with hierarchical porosity for medical applications: Review of recent advances. Acta Biomater. 2016, 42, 18-32. [CrossRef] [PubMed]

26. Yoda, Y.; Hu, Z.-Q.; Shimamura, T.; Zhao, W.-H. Different susceptibilities of Staphylococcus and Gram-negative rods to epigallocatechin gallate. J. Infect. Chemother. 2004, 10, 55-58. [CrossRef]

27. Chu, C.; Deng, J.; Hou, Y.; Xiang, L.; Wu, Y.; Qu, Y.; Man, Y. Application of PEG and EGCG modified collagen-base membrane to promote osteoblasts proliferation. Mater. Sci. Eng. C 2017, 76, 31-36. [CrossRef] 